\title{
Repair Delaminations in Carbon/epoxy Laminates
}

\author{
A.M. Amaro ${ }^{1}$, M.A. Neto ${ }^{1}$, A.J.R. Loureiro ${ }^{1}$, M.P. Silva ${ }^{2, a}$ and P.N.B. Reis ${ }^{2}$ \\ ${ }^{1}$ CEMMPRE, Depart. of Mechanical Engineering, University of Coimbra, Rua Luís Reis Santos, Pinhal Marrocos, \\ 3030-788 Coimbra, Portugal \\ ${ }^{2} C-M A S T$, Depart. of Electromechanical Engineering, University of Beira Interior, Covilhã, Portugal
}

\begin{abstract}
Delaminations are the most typical damage in composite laminates, and the industrial community is continually searching new techniques to combine efficiency with cost benefits. Therefore, this work intends to analyse the application of screws on repair of composite laminates containing delaminations. It was found that this technique is beneficial for delaminations with lengths higher than $15 \mathrm{~mm}$. For example, considering delaminations with $20 \mathrm{~mm}$, the compressive load increases around $46.4 \%$ relatively to the delaminated samples. However, for small lengths, this technique is not viable due to the stress concentration induced by the hole.
\end{abstract}

\section{Introduction}

Delaminations between different oriented layers are the most typical damage that occurs in composite laminates. In this context, literature reports several techniques with the purpose to restore the damaged component for a usable condition.

Traditionally it is used the bonded repairs, where the adhesive layer transfer some load from one part of the component to other one reducing, in this case, the stresses in the repaired component. Mainly two types of patch configurations are available: the scarf patches and the overlap patch [1-4]. However, according to Soutis et al. [2], the external patch technique is simpler to apply and is less critical in nature than a scarf method.

The resin injection repair is also regarded as a temporary measure to prevent the spread of damage until further maintenance can be performed $[5,6]$. For this purpose, the novel cyanoacrylates bring significant benefits due to the very low viscosity at room temperature and relatively high glass transition temperature [6,7]. However, some inconvenient are preferred by Wu et al. [8] due to the fact that during the injection the surfaces of the delaminations can be contaminated by the environment, making any bonding ineffective. A more effective alternative is the through-thickness reinforcement repair (TTRR), proposed by $\mathrm{Li}$ et al. [9]. In this case, holes are drilled through the delaminated region and pins bonded into these holes. According to the authors, it is hypothesised that the pins will effectively shorten the length of the sub-laminates and increases the load at which they buckle [9].

Finally, self-healing is a novel alternative to damage tolerant design and removes the need to perform temporary repairs to damaged structures, where an autonomous healing functionality into a composite material is made [10]. In this case the damaged structure is repaired by materials already

\footnotetext{
${ }^{\mathrm{a}}$ Corresponding author: marco.silva@ubi.pt
} 
contained within it, analogous to the biological healing process in living organisms [11]. An ideal selfhealing material is capable to restore the material's performance without affect the initial mechanical properties [12].

However, the industrial community is continually open to new techniques, especially when they combine the efficiency with cost benefits. In this context, the aim of the present work is to study the efficiency of delaminations repaired by application of screws. It is known that the delaminations do not affect the laminate behaviour if the adjacent faces tend to close under normal compression. Based in a similar philosophy to the through-thickness reinforcement method, it is expected to restore the mechanical strength required to permit the component operation until a permanent repair can be done.

\section{Materials and Procedure}

Composite laminates were manufactured using 12 balanced woven bi-directional layers of carbon fibres $\left(196 \mathrm{~g} / \mathrm{m}^{2}\right)$ all of them with the same orientation $0 / 90^{\circ}$, and an epoxy resin matrix. Details about the manufacture process of the composites laminates can be found in [13]. Delaminations were simulated by a Teflon layer, at the middle of the plate's thickness, with lengths of 2, 5, 10, 15, and 20 $\mathrm{mm}$ as described in [14]. Similar samples were manufactured and, using a special drill, open holes with $3 \mathrm{~mm}$ of diameter were introduced in the middle of the delamination length. M3 screws were inserted as shown in Figure 1.

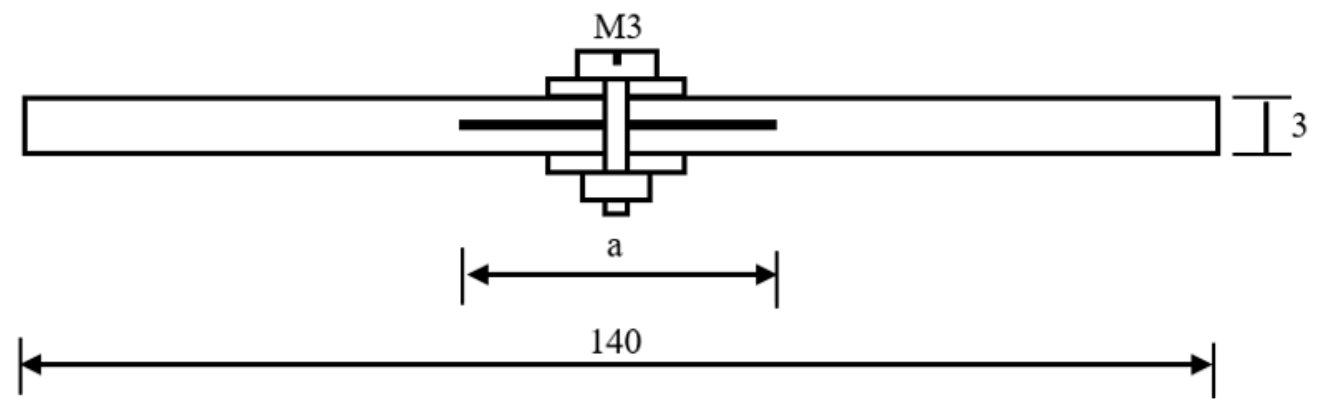

Figure 1. Geometry of the specimens in $\mathrm{mm}$. The samples width is $140 \mathrm{~mm}$ and the delamination length (a) of 2 , $5,15,20 \mathrm{~mm}$.

The compressive tests were performed using an Instron 4206 universal tensile testing machine in accordance with the standard ASTM D 3410-03. All the tests were performed at room temperature with a strain rate of $1.5 \mathrm{~mm} / \mathrm{min}$. Global strain data of the specimens was evaluated using a $50 \mathrm{~mm}$ gauge length clip-on extensometer in a length between grips of $80 \mathrm{~mm}$. Local strain data acquisition was performed using an Aramis 3D 5M optical system (GOM GmbH) with Digital Image Correlation (DIC). So, full-field displacements of the overlap region could be measured. It should be noted that before testing, the specimens were prepared by applying a random black speckle pattern, over the previously mat white painted surface of the samples, in order to enable data acquisition by DIC [15].

\section{Results and discussion}

Figure 2 shows typical compressive load-displacement curves relatively to the specimens with a delamination of $15 \mathrm{~mm}$, however, they are representative of all tests. The maximum loads obtained are compared in Figure 3, where symbols represent the average values and the scatter bands the maximum and minimum values obtained.

It is possible to observe a significant decreasing of the maximum load with the presence of delaminations and with their length. For example, between 15 and $20 \mathrm{~mm}$, the compressive strength presents values very close and around 52\% lower than the ones observed for the control samples. 


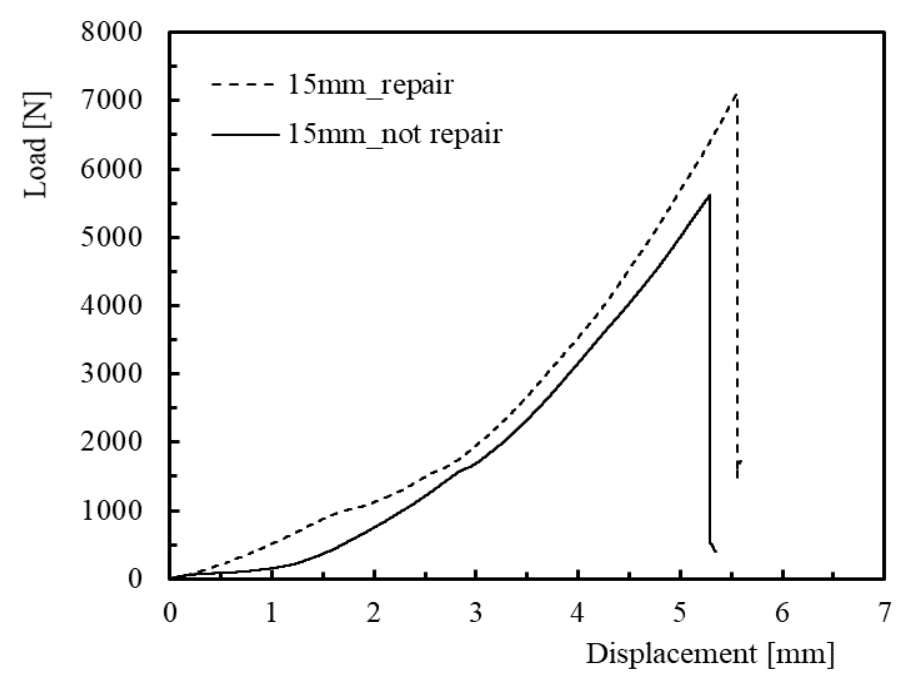

Figure 2. Typical load-displacement curves obtained from the compressive tests.

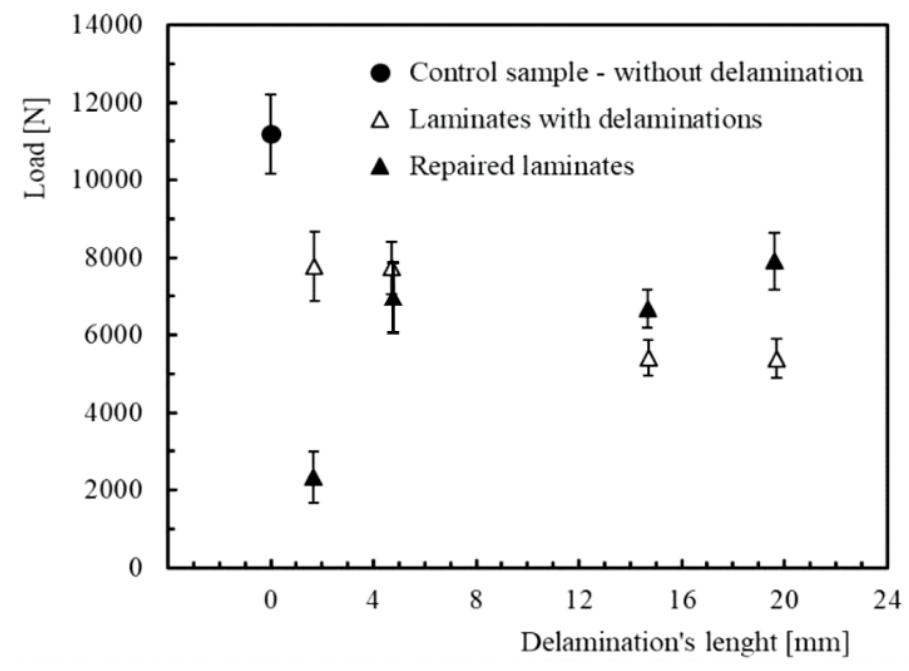

Figure 3. Comparison between laminates with delaminations against repaired laminates in terms of maximum compressive load.

These results are in good agreement with a previous study developed by the authors, where a significant reduction of the compressive strength was observed with the presence of similar defects [16]. Stress concentration promoted by the delaminations is responsible by the decrease observed on the compressive strength [17], however, the failure mechanisms show to be determinant on such process. According with the literature, delaminations under compressive loads can cause buckling in one of three modes: global instability/buckling of the laminate, local instability (buckling of the sublaminate), or a combination of them [18, 19]. However, the delamination shape [20-22] and the laminate stacking sequence [23] show to be an important factor on the failure mode observed. Amaro et al. [16], for example, observed local buckling as the main failure in laminates containing throughthe-width delaminations, i.e., buckling of the sub-laminate delaminated. In this case, delaminations tend to grow rapidly leading to the structural failure [24]. Similar phenomenon was found in the present study, as shown in Figure 4. Figure 4a) shows the typical final failure occurred in samples with delaminations, while Fig 4b) shows the delamination with $15 \mathrm{~mm}$ of length, respective 
propagation during the initial loading values and, simultaneously, the initial buckling of a sub laminate delaminated.
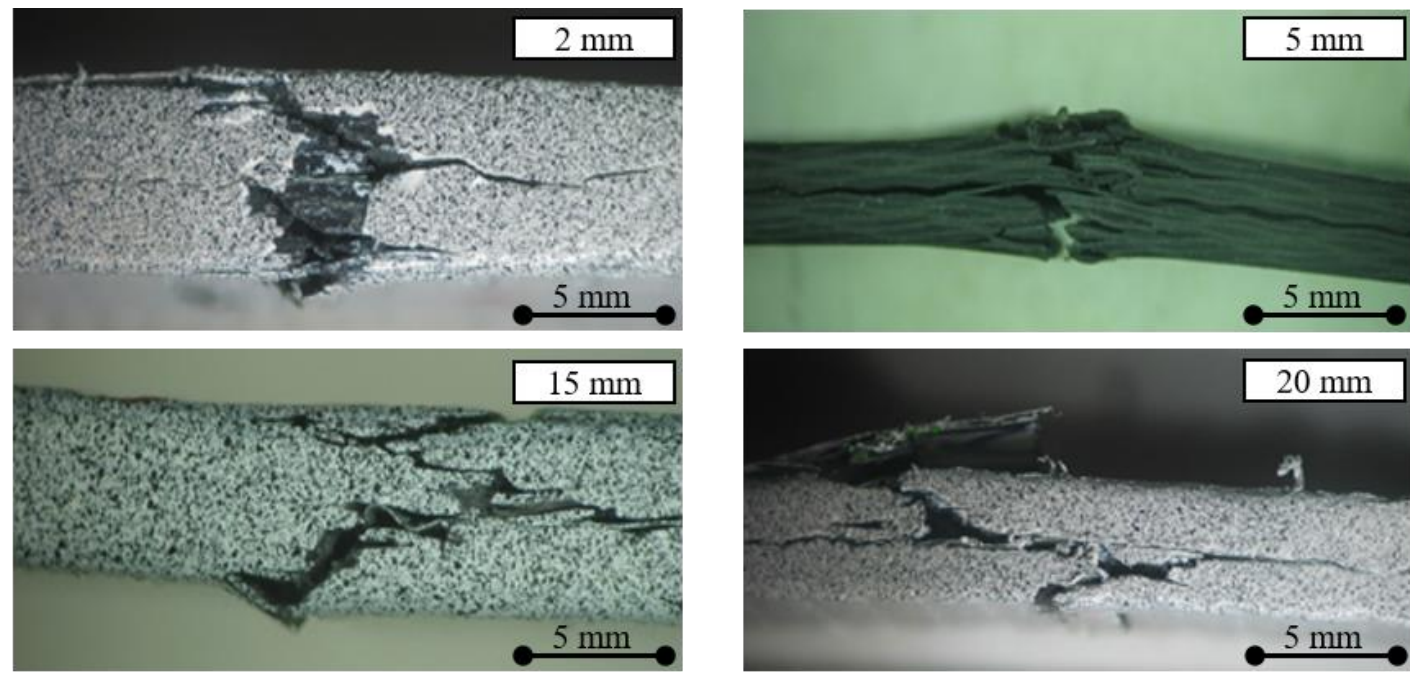

a)

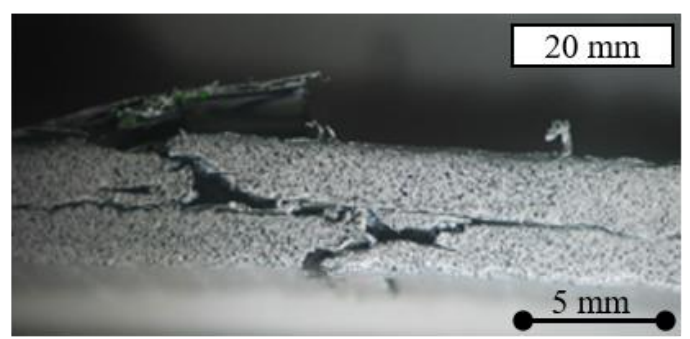

$\log$
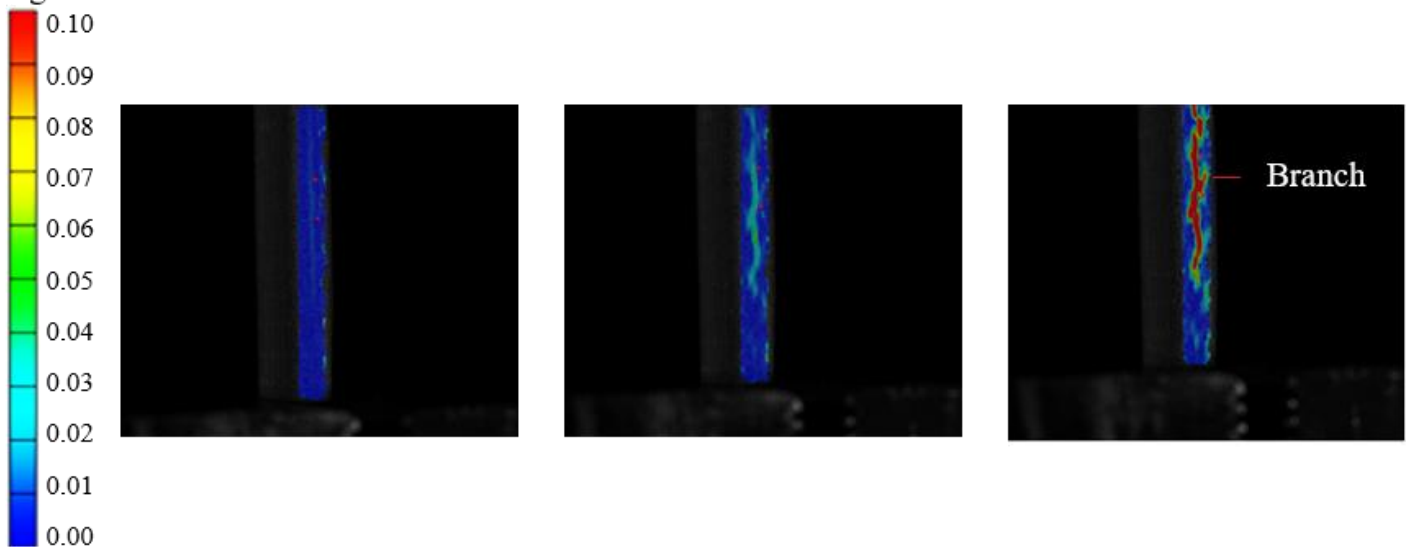

b)

Figure 4. a) Typical final failures for laminates with delamination; b) Sequence of the damage progretion for the initial loading obtained for $15 \mathrm{~mm}$ of delaminations's length.

Relatively to the samples repaired by screws, as shown in Figure 3, it is possible to observe a significant drop of the compressive strength for samples with delaminations of $2 \mathrm{~mm}$. A decreasing around $70 \%$ is observed comparatively to the samples with delamination, which is expected as consequence of the hole necessary to the screw to be higher than the delamination's length. Similar tendency was observed for delaminations with $5 \mathrm{~mm}$ but, in this case, only a slight decreasing about $4.5 \%$ was found. However, for higher values a positive effect of the screw is visible, indicating this technique as solution to repair laminates composites with delaminations. For delaminations with 15 and $20 \mathrm{~mm}$ of length, the compressive load increases around $23.4 \%$ and $46.4 \%$, respectively, compared to the delaminated samples.

Figure 5 shows the typical final failures observed for samples repaired, which are different from the ones occurred for samples with delaminations. 

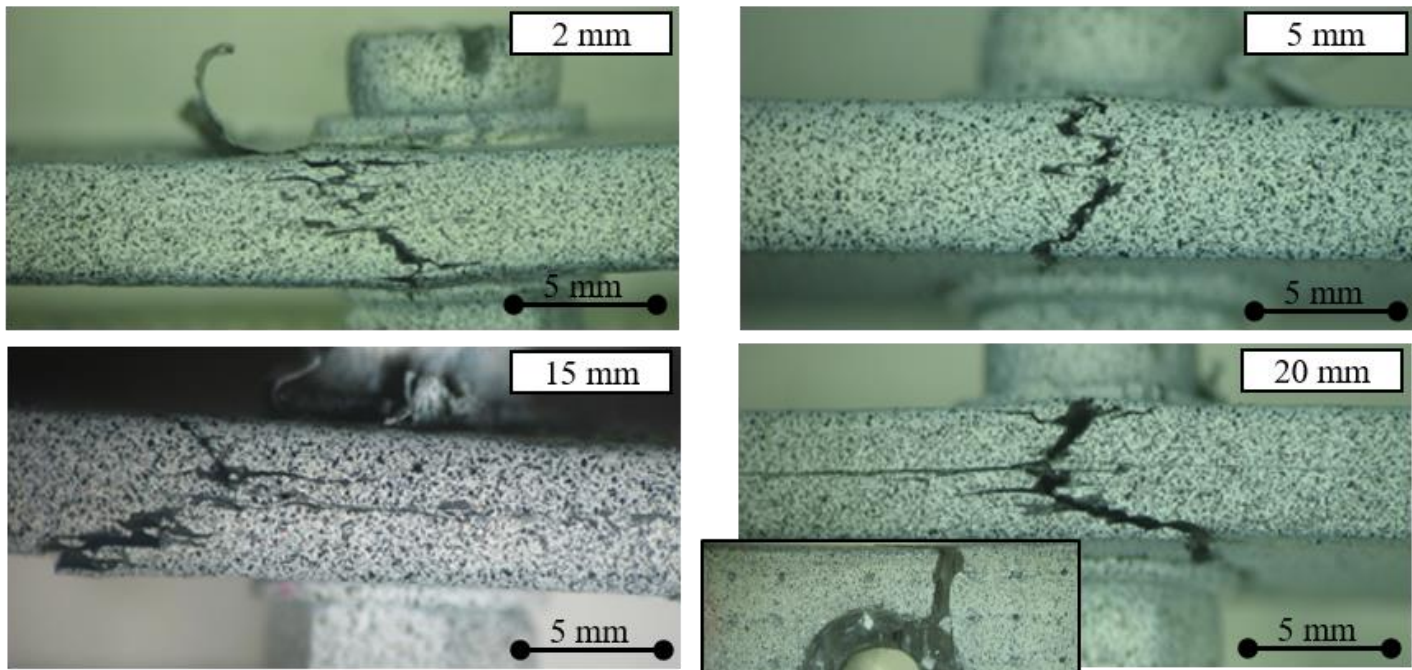

a)
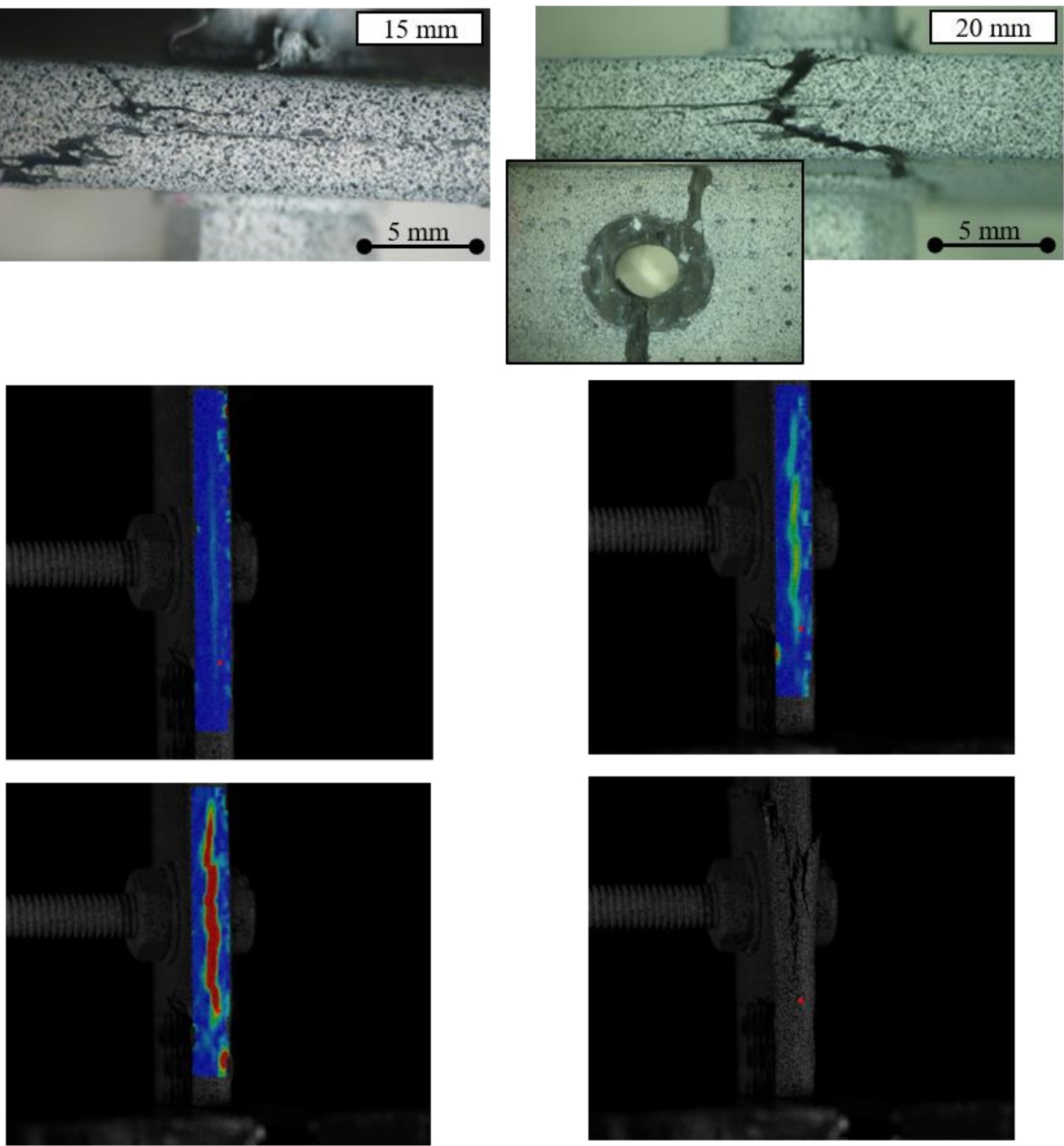

b)

Figure 5. a) Typical final failures for repaired laminates; b) Sequence of the damage progretion obtained for 15 mm of delaminations's length.

In this case, the screw prevents the opening of the delamination and the buckling is not the main damage mechanism. As shown in Figure 5a), the damage is essentially localized in the region of the screw, for all configurations, because the holes promote stress concentrations responsible by the 
damages occurred around their border [25]. Figure 5b) evidences the evolution of the damage for samples with delaminations of $15 \mathrm{~mm}$, where is visible the severity of the damage near the screw.

\section{Conclusions}

The focus of this study was to evaluate the possibility to repair composite laminates containing delaminations. For this purpose, a new technique using screws was suggested in order to solve the most typical damage in such materials.

It was possible to conclude that the present technique is not viable for small delamination lengths, as consequence of the stress concentration induced by the hole, but for delaminations higher than 15 $\mathrm{mm}$ shows to be efficient. However, more research works should be performed to obtain a complete knowledge, in order to make feasible its application on real conditions.

\section{References}

1. P. Cheng, X.-J. Gong, D. Hearn, S. Aivazzadeh, Compos. Struct. 93, 582 (2011).

2. C. Soutis, D.-M. Duan, P. Goutas, Compos. Struct. 45, 289 (1999).

3. F.Z. Hu, C. Soutis, Compos Sci Technol. 60, 1103 (2000).

4. S.R.M. Coelho, P.N.B. Reis, J.A.M. Ferreira, A.M. Pereira, Compos. Struct. 168, 259 (2017).

5. M. Hautier, D. Lévêque, C. Huchette, P. Olivier, Plast. Rubber Compos. 39, 200 (2010).

6. S.M. Bleay, C.B. Loader, V.J. Hawyes, L. Humberstone, P.T. Curtis, Compos Part A-Appl S. 32, 1767 (2001).

7. P.G. Slattery, C.T. McCarthy, R.M. O’Higgins, Compos. Struct. 153, 1 (2016).

8. K.-W. Wu, C.-L. Lee, Y.-C. Chang, C.-L. Ong, Mater. Chem. Phys. 43, 173 (1996).

9. H.C.H. Li, P.J. Callus, I. Herszberg, Compos. Struct. 75, 539 (2006).

10. G. Williams, R. Trask, I. Bond, Compos Part A-Appl S. 38, 1525 (2007).

11. J.W.C. Pang, I.P. Bond, Compos. Sci. Technol. 65, 1791 (2005).

12. D.Y. Wu, S. Meure, D. Solomon, Prog. Polym. Sci. 33, 479 (2008).

13. P.N.B. Reis, J.A.M. Ferreira, J.D.M. Costa, M.O.W. Richardson, Compos. Sci. Technol. 69, 1541 (2009).

14. P.N.B. Reis, , J.A.M. Ferreira, F.V. Antunes, M.O.W. Richardson, J. Compos. Mater. 43, 2609 (2009).

15. C. Leitão, M.I. Costa, K. Khanijomdi, D.M. Rodrigues, Mater. Des. 51, 968 (2013).

16. A.M. Amaro, P.N.B. Reis, M.F.S.F. de Moura, M.A. Neto, Fiber Polym. 15, 560 (2014).

17. T.K. O’Brien, M. Rigamonti, C. Zanotti, Int. J. Fatigue 11, 379 (1989).

18. C. Soutis, P.T. Curtis, Compos. Sci. Thecnol. 56, 677 (1996).

19. C. Soutis, F.C. Smith, F.L. Matthews, Compos. Part A-Appl S. 31, 531 (2000).

20. M.J. Pavier, W.T. Chester, Composites 21, 23 (1990).

21. E.S. Greenhalgh, Compos. Struct. 23, 165 (1993).

22. G.J. Short, F.J. Guild, M.J. Pavier, Compos. Sci. Technol. 61, 2075 (2001).

23. A. Tafreshi, T. Oswald, Int. J. Pres. Ves. Pip. 80, 9 (2003).

24. S.-Y. Lee, D.-Y. Park, Int. J. Solids Struct 44, 8006 (2007).

25. C. Soutis, N.A. Fleck, P.A. Smith, J. Compos. Mater. 25, 1476 (1991). 